\title{
CARACTERÍSTICAS DO GERENCIAMENTO DOS RESÍDUOS SÓLIDOS DOS SERVIÇOS DE SAÚDE EM CURITIBA E ANÁLISE DAS IMPLICAÇÕES SOCIOAMBIENTAIS DECORRENTES DOS MÉTODOS DE TRATAMENTO E DESTINO FINAL
}

\author{
Management's characteristics of Curitiba's solid bio-medical waste \\ residues and the social and environmental implications resulting \\ from the method of treatment and final disposal
}

\author{
Maria Inez Antonia Pelacani SPINA ${ }^{1}$
}

\begin{abstract}
RESUMO
Este artigo $^{2}$ apresenta as características do gerenciamento integrado dos Resíduos Sólidos dos Serviços de Saúde (RSSS), desenvolvido pelo Poder Público e empresas de saúde de Curitiba, durante o período de 1989 a 2001, e analisa os problemas socioambientais que as etapas referentes ao manejo, tratamento e destino final dos resíduos infectantes podem causar ao ambiente e à saúde pública ao longo do tempo. Constatou-se, ao final do período analisado, que apenas 862 empresas de saúde de Curitiba encontravam-se devidamente cadastradas ao programa de coleta seletiva denominado "Lixo que não é lixo hospitalar", havendo necessidade de ampliação desses serviços a todas as empresas de saúde geradoras de resíduos infectantes existentes no município, mediante cadastramento ao programa. Ressalta também que o monitoramento periódico das condições físico-ambientais da área das valas sépticas, método de destino final dos resíduos infectantes, é de fundamental importância para se dimensionarem as reais condições dos componentes físicos dessa área e para serem evitados os efeitos nocivos da decomposição dos resíduos patogênicos ao ambiente e à qualidade de vida da população.
\end{abstract}

\section{Palavras-chave:}

Resíduos sólidos dos serviços de saúde, gerenciamento, destino final, meio ambiente.

\begin{abstract}
This paper focuses the integrated management's characteristics of solid bio-medical waste residues developed by the government and health companies from Curitiba during 1989 till 2001, and it analyzes social and environmental problems that the steps relating to handling, treatment and final disposal of infected residues can cause to the ambient and public health. After the period analyzed, the results shows just 862 health companies from Curitiba were registered at "Lixo que não é lixo hospitalar", a local program of selective waste collect. This made clear the necessity of growing for this service to register all health companies that produce infecting residues in the city. Besides, this paper points out the importance of periodic verifications for the sanitary landfill's conditions (final disposal's method for infecting residues) to indicate the real conditions of the physical parts present on this area, and avoid the malign effects resulting from the pathogenic residues' decomposition on the environment and to population's life quality.
\end{abstract}

\section{Key-words:}

Solid bio-medical residues, management, final disposal, environment.

1 Pós-graduada em Educação - IBPEX - Curitiba; Especialista em Gestão e Análise Ambiental - Departamento de Geografia - UFPR; Mestre em Geografia - Departamento de Geografia - UFPR; atividades docentes na área de Geografia no Ensino Fundamental, Médio e Superior, da rede pública e privada de Curitiba-PR <mispina@uol.com.br>

2 Este trabalho constitui-se em uma síntese da dissertação de Mestrado em Geografia - Departamento de Geografia da UFPR concluído em 2003, sob orientação da Professora Doutora Sony Cortese Caneparo. 


\section{INTRODUÇÃO}

Os resíduos sólidos de serviços de saúde - RSSS gerados nos centros urbanos, apesar de baixa representatividade ( $2 \%$, aproximadamente) perante a produção total dos resíduos sólidos urbanos - RSU, constitui-se em um dos sérios problemas a ser gerenciado pelas empresas prestadoras de serviços na área da saúde e, circunstancialmente, pelo Poder Público local. Parte desses resíduos, pelas características patogênicas que apresentam, requer cuidados e técnicas especiais em todas as fases de seu manuseio, sobretudo quanto aos métodos utilizados no destino final, a fim de evitar que os efeitos nocivos de sua decomposição causem danos ao ambiente e à qualidade de vida de sua população, em curto, médio e longo prazos.

A Resolução Conama 283/01, reiterando a Resolução Conama 05/93, considera que os RSSS são aqueles provenientes de qualquer unidade que execute atividades de natureza médico-assistencial humana ou animal, gerados em centros de pesquisa, desenvolvimento ou experimentação na área de farmacologia e saúde, incluindo-se os medicamentos e imunoterápicos vencidos ou deteriorados, e ainda os resíduos provenientes de necrotérios, funerárias, serviços de medicina legal e de barreiras sanitárias.

AAgência Nacional de Vigilância Sanitária -Anvisa, pela Resolução da Diretoria Colegiada - RDC n' 306/04 indica detalhadamente, em seu Regulamento Técnico, os procedimentos corretos que devem ser acatados pelas empresas prestadoras de serviços de saúde quanto ao gerenciamento dos RSSS, atendendo assim às normas e exigências legais, desde o momento da geração até a destinação final desses resíduos.

A origem dos RSSS ocorre nas unidades internas das empresas prestadoras de serviços relacionados ao atendimento à saúde humana ou animal, dentre os quais destacam-se os hospitais, os postos de saúde, os laboratórios de análises clínicas, as drogarias, as farmácias, os ambulatórios, as clínicas médicas, veterinárias e odontológicas, os estabelecimentos de ensino e pesquisa na área de saúde, os necrotérios e funerárias, os serviços de assistência domiciliar e de trabalho de campo, dentre outras (RDC 306/04).

Esses resíduos são classificados em cinco grandes grupos, de acordo com as características que apresentam. Pertencem ao grupo A (subdividos de A1 a A5) aqueles que apresentam riscos à saúde pública e ao meio ambiente devido à presença de agentes biológicos. $\mathrm{O}$ grupo $\mathrm{B}$ abrange a categoria de resíduos que contêm substâncias químicas que podem apresentar risco à saúde pública e ao meio ambiente devido às suas características de inflamabilidade, corrosividade, reativi- dade e toxicidade. O grupo C é composto pelos resíduos resultantes de atividades humanas que contenham radionuclídeos em quantidades superiores aos limites de isenção especificados nas normas do Conselho Nacional de Energia Nuclear (CNRN) para os quais a reutilização é imprópria ou não prevista. O grupo $D$ abrange a totalidade de resíduos que não apresentam risco biológico à saúde e ao meio ambiente, podendo ser equiparados aos resíduos domiciliares. O grupo $\mathrm{E}$ corresponde aos materiais perfuro-cortantes ou escarificantes, tais como lâminas, espátulas, agulhas, escalpes, ampolas de vidro, limas endodônticas, e demais resíduos similares (RDC 306/04).

As características físicas, químicas e microbiológicas dos RSSS estão intimamente relacionadas à sua composição e à sua fonte geradora. No entender de Bertussi Filho (1994, p. 15), o conhecimento das particularidades patogênicas e infectantes desses resíduos é de fundamental importância nas etapas referentes ao manuseio, tratamento e disposição final como fator preponderante para a preservação das condições naturais do meio ambiente, bem como à qualidade de vida dos moradores das áreas vizinhas aos locais geradores de destino final de tais resíduos.

O gerenciamento de RSSS, conforme disposto no art. 4 da Resolução Conama 05/93, mantido no art. 4 da Resolução Conama 283/01 e reiterado na RDC 306/04, é de responsabilidade das empresas geradoras desses resíduos. No entanto, partir de 1989 o Poder Público de Curitiba, visando garantir coleta, transporte, tratamento e destino final adequados, assumiu parte desse gerenciamento, mediante o compromisso dessas empresas em aderir e acatar as normas do programa de coleta seletiva desenvolvido pela municipalidade.

O presente trabalho, tomando por base a análise das atividades decorrentes dessa parceria, destaca as características gerais e as implicações socioambientais do gerenciamento dos RSSS que se evidenciaram ao longo do período contemplado nesta pesquisa, ou seja, de janeiro de 1989 a dezembro de 2001 , sobretudo no que se refere aos impactos decorrentes do tratamento e destino final dos resíduos infectantes ou patogênicos.

\section{GERENCIAMENTO DE RSSS EM CURITIBA}

O gerenciamento dos RSU desenvolvido pelo Poder Público do município de Curitiba insere-se na denominada Gestão Integrada de Resíduos Sólidos, pela qual, segundo Ibam (2001, p. 4), "o poder local busca gerenciar o lixo de forma a permitir que os aspectos sociais e ambientais sejam contemplados e integrados ao planejamento das ações técnicas e operacionais do sistema de limpeza urbana". 
Dessa forma, a partir de 1989, foram criados em Curitiba vários programas de coleta de RSU, dentre os quais o programa de coleta seletiva de RSSS, denominado "Lixo que não é lixo hospitalar", estabelecendo-se, então, uma parceria do Poder Público local, representado pela Secretaria Municipal do Meio Ambiente - SMMA, sob responsabilidade técnico - operacional do Departamento de Limpeza Pública, e empresas prestadoras de serviços de saúde desse município. Às empresas de saúde coube a função de gerenciar os RSSS nas fases compreendidas pela geração, segregação, acondicionamento, transporte interno e armazenagem externa desses resíduos. Ao Poder Público reservou-se a responsabilidade de gerenciá-los nas fases de coleta externa, transporte, tratamento e destino final (SPINA, 1999, p. 70).

A figura 1 demonstra os agentes envolvidos nas diversas etapas referentes ao gerenciamento dos RSSS em Curitiba, bem como as possíveis implicações causadas ao ambiente e à saúde da população.

As empresas prestadoras de serviços de saúde de Curitiba, enquanto entidades geradoras de RSSS, ficaram responsáveis pelas fases internas dos serviços referentes à geração, segregação, acondicionamento, coleta interna, transporte interno e abrigo ou armazenamento externo dos mesmos. A fiscalização referente ao manejo ou gerenciamento interno ficou sob a incumbência da Comissão de Controle de Infecção Hospitalar - CCIH e pela Comissão Interna de Prevenção de Acidentes - Cipa, sintonizadas com as normas dos serviços de higiene e limpeza, em estrita observância aos parâmetros legais em vigor. Dessa forma, os resíduos gerados nessas empresas, ao serem descartados, passaram a ser submetidos ao processo de seleção e segregação conforme a categoria a que pertencem: orgânicos ou domésticos, infectantes e recicláveis.

O Poder Público municipal, na condição de agente gerenciador, responsabilizou-se pelas fases compreendidas pela coleta externa, transporte definitivo, tratamento e destino final dos RSSS, além do treinamento dos funcionários das empresas de saúde cadastradas ao programa de coleta seletiva, quanto aos procedimentos corretos a serem acatados referentes ao manejo desses resíduos. Os serviços de coleta, transporte, tratamento e destino final, terceirizados, passaram a ser realizados pela empresa Companhia Auxiliar de Viação e Obras Cavo. A coleta realizada em cada empresa prestadora de serviço de saúde ocorre de uma a sete vezes por semana, de acordo com o volume de resíduos gerados.

FIGURA 1-RESPONSABILIDADES TÉCNICO-OPERACIONAIS PELOS RSSS EM CURITIBA

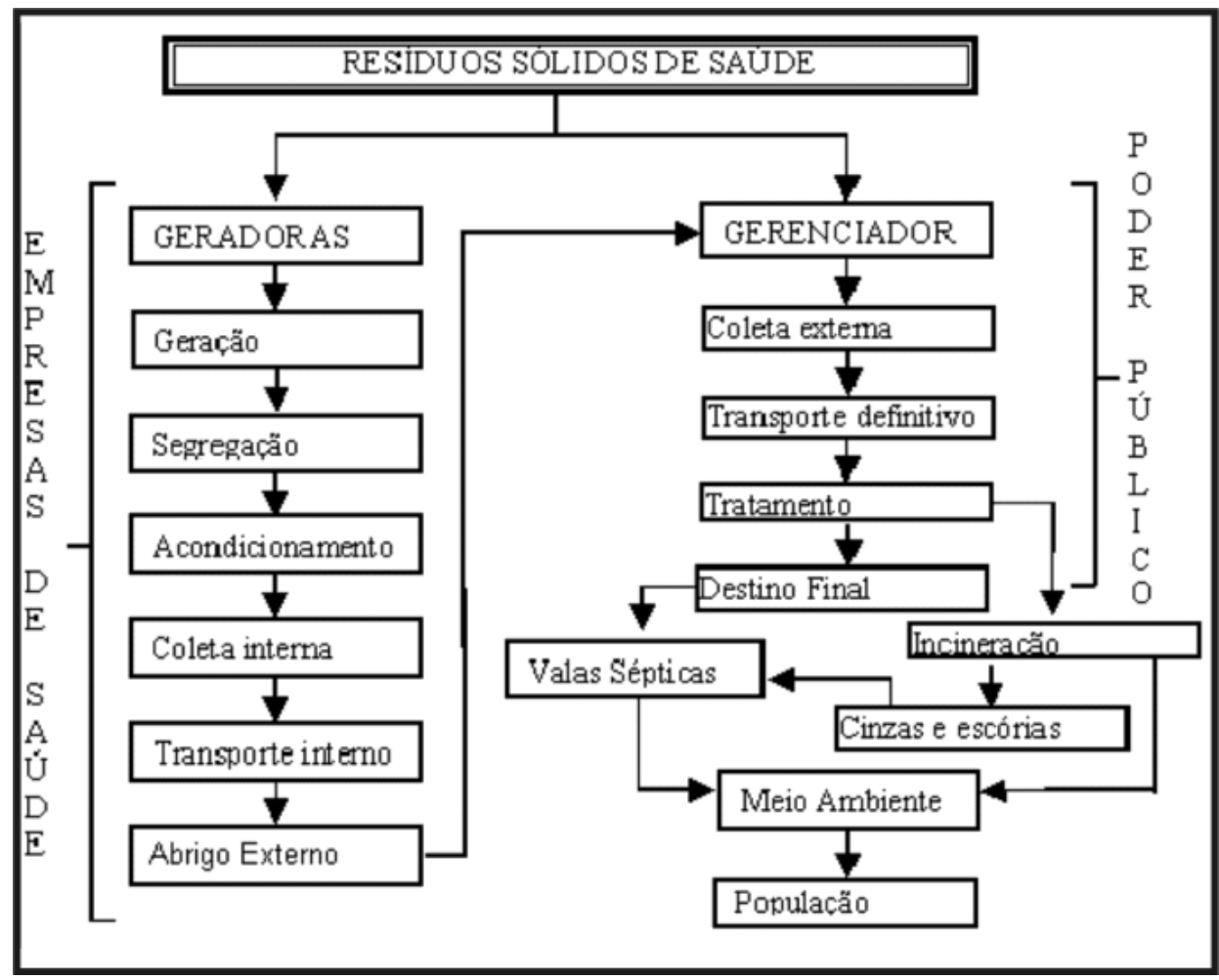

FONTE: SPINA, 2003, p. 96 
Abordando o período compreendido entre janeiro de 1989 (início dos programas de coleta seletiva de RSU e RSSS) a dezembro de 2001 (término da utilização do método de incineração de resíduos infectantes em equipamento móvel), a pesquisa realizada constatou que em Curitiba, ao final de 2001, existiam 6.272 empresas de saúde, das quais 862 devidamente cadastradas ao programa de coleta seletiva desenvolvido pelo Poder Público local, destacando-se dentre elas a totalidade da categoria representada pelos hospitais, maiores geradores de RSSS do município. (SPINA, 2003, p. 67).

A espacialização das empresas cadastradas no programa de coleta seletiva apresenta-se altamente concentrada, sobretudo nos bairros centrais de Curitiba, exceto a categoria representada pelos postos de saúde, presentes em quase todos os bairros (mapa 1).

Estão representadas no mapa 1 todas as categorias de empresas de saúde de Curitiba cadastradas ao

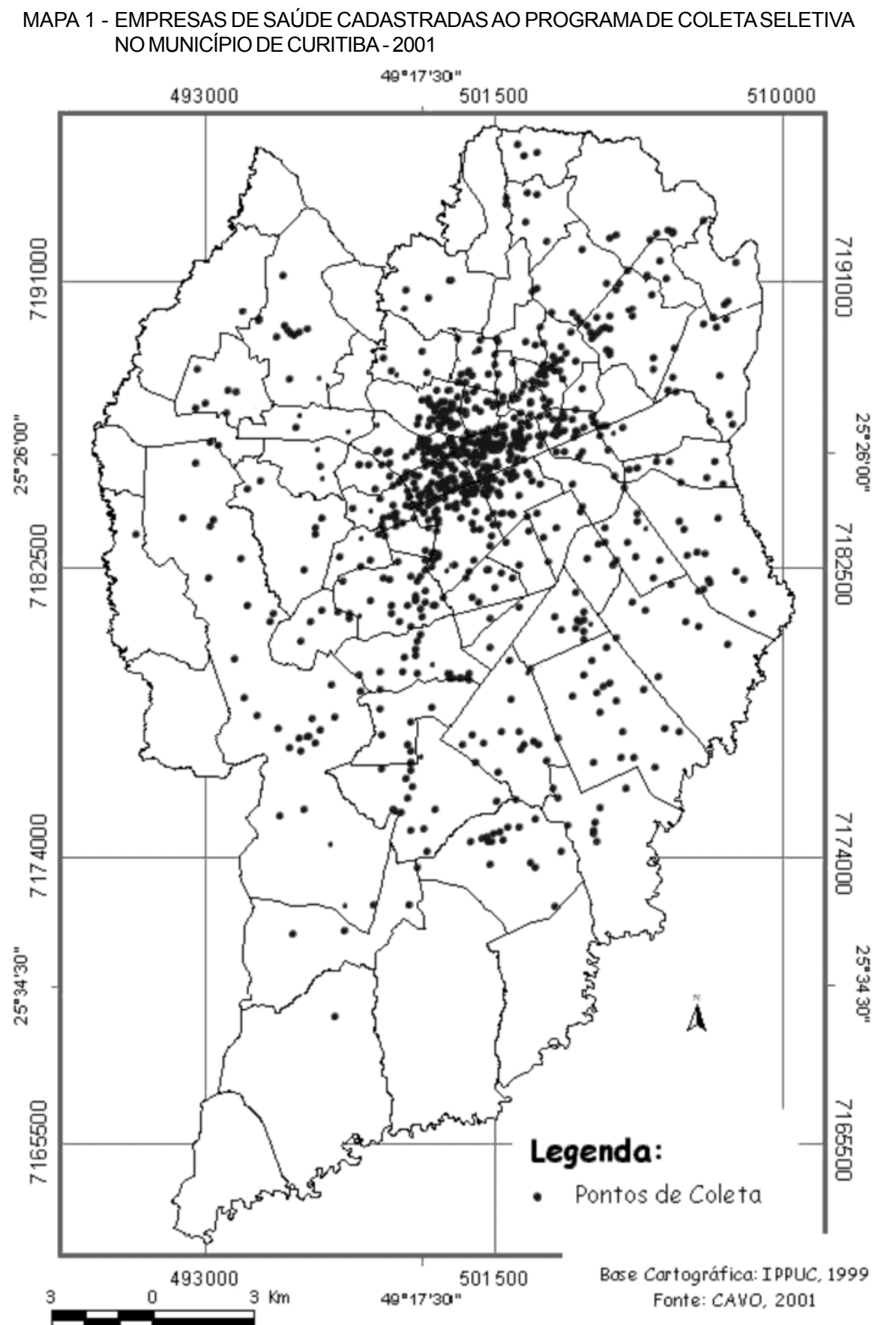


programa de coleta seletiva: 216 clínicas odontológicas, 192 clínicas médicas, 109 unidades de saúde, 51 laboratórios, 47 farmácias, 44 hospitais, 13 clínicas veterinárias, 5 asilos e 5 unidades da Associação Saza Lates, além de 180 demais empresas de outras categorias, tais como escolas, aeroportos, condomínios residenciais, universidades-escola, shopping centers e ambulatórios (SPINA, 2003, p. 67).

\section{GERAÇÃO DE RSSS PELAS EMPRESAS DE SAÚDE}

A criação e aplicação do programa de coleta seletiva "Lixo que não é lixo hospitalar" em Curitiba, em 1989, introduziram novos conceitos a respeito dos RSSS, colaborando com a desmistificação da idéia de que todos os resíduos gerados em empresas de saúde são necessariamente infectantes. Dessa forma, o referido programa oferece suporte teórico, técnico e operacional para que, mediante segregação, acondicionamento, coleta e armazenagem dos diferentes resíduos gerados pelas empresas de saúde, sobretudo dos hospitais, onde ocorre internação de pacientes, possam ser destinados adequadamente, de acordo com as características apresentadas por cada categoria de resíduos, conforme pode ser observado na figura 2.

A maior parte dos RSSS são produzidos em áreas não ocupadas por pacientes, tais como cozinha, onde são gerados cerca de 50 \% dos resíduos, considerados comuns; 14 \% provém de áreas administrativas, sem acesso direto de pacientes, podendo ser reciclados, e somente $36 \%$ correspondem aos resíduos infectantes e patogênicos, oriundos de áreas ocupadas por pacientes, tais como enfermarias, maternidades, ortopedias e centros cirúrgicos. Dessa forma, conhecendose suas particularidades, é possível conceder destinos finais apropriados a cada categoria de resíduos gerados.

Em Curitiba, os resíduos comuns, provenientes dos serviços de preparo de alimentos realizados na cozinha, são coletados e transportados ao aterro sanitário da Cachimba, onde são aterrados. Os resíduos recicláveis são coletados e encaminhados à usina de reciclagem existente no município de Campo Magro (Região Metropolitana de Curitiba) ou comercializados diretamente pelas empresas geradoras. Os resíduos infectantes são coletados por profissionais treinados e transportados por caminhões apropriados à área das valas sépticas, nas quais são aterrados em seu destino final.

\section{TRATAMENTO DE RSSS EM CURITIBA}

De acordo com a Resolução Conama 05/93, compreende-se por sistema de tratamento de resíduos sólidos o "conjunto de unidades, processos e procedimentos que alteram as características físicas, químicas ou biológicas dos resíduos e conduzem à minimização do risco à saúde pública e à qualidade do meio ambiente".

FIGURA 2 - PARTICIPAÇÃO DAS UNIDADES DE UM HOSPITAL NA GERAÇÃO DE RSSS

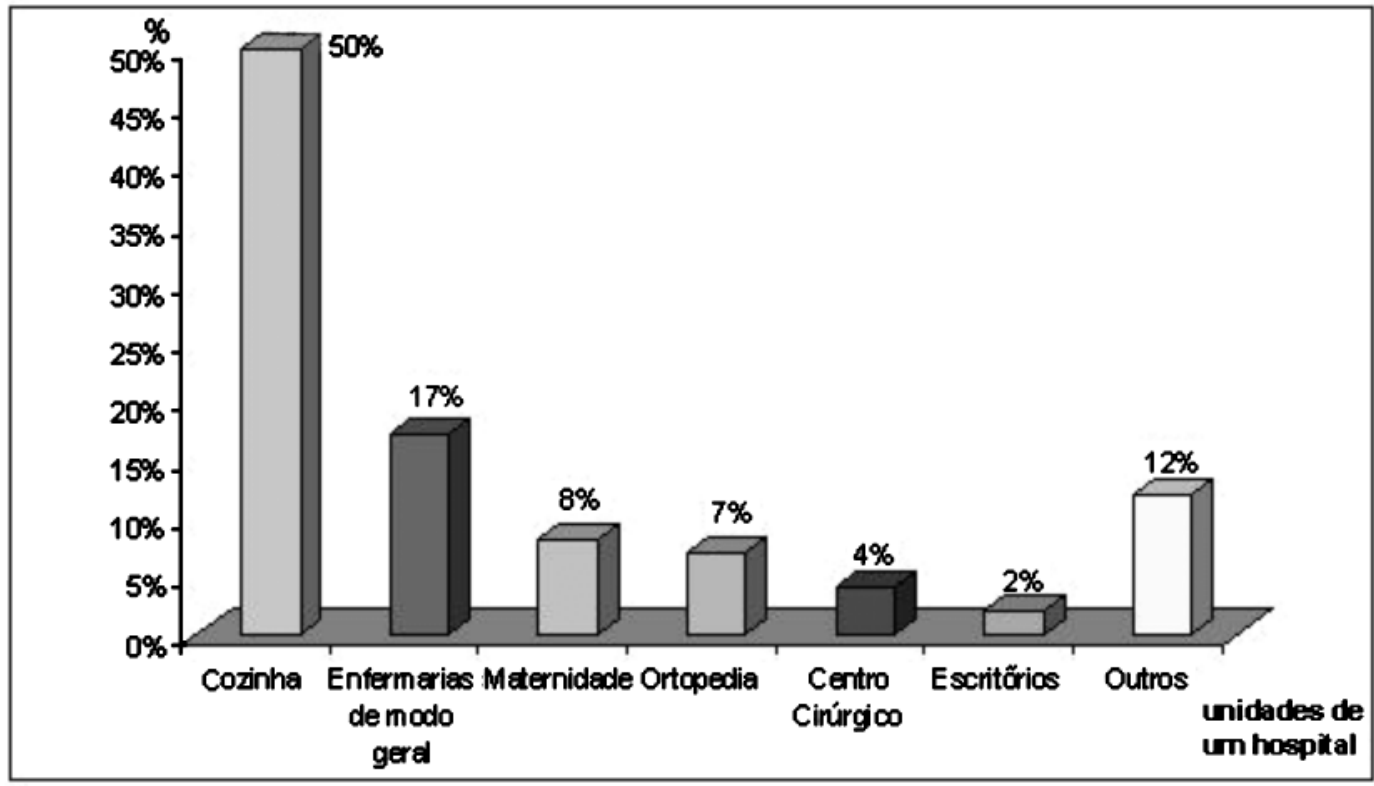

FONTE: ADAPTADO DE MACHADO JUNIOR E SOBRAL, 1978 in: BERTUSSI FILHO, 1994, p. 30, 
Dentre os vários métodos de tratamento de RSSS (autoclave, microondas, desinfecção química, radiação ou ionização), destaca-se a incineração, pela sua eficiência em exterminar definitivamente os agentes patogênicos (BERTUSSI FILHO, 1994, p. 54; CALDERONI, 1998, p. 133).

Em Curitiba, no período de 1996 a 2001, utilizouse o método representado pela incineração em equipamento móvel, ou seja, caminhões tecnicamente adequados para essa finalidade, como forma de tratamento de parte de RSSS, sobretudo os resíduos pertencentes aos grupos denominados de perfuro-cortantes; sangue e hemoderivados; cirúrgico, anatomo-patológico e exsudado; biológico e resultantes de assistência ao paciente (PMC, 1999, p. 17).

Pelo sistema de rotatividade diária, estacionados principalmente em pátios de hospitais pré-selecionados, cinco caminhões processavam a incineração dos resíduos infectantes produzidos por esse e demais hospitais e empresas de saúde situadas nas proximidades. Os dez locais onde a incineração era processada concentravamse em bairros fortemente urbanizados, próximos ao centro da cidade, representados pelo Horto Florestal (Guabirotuba), Unidade de Saúde do Campo Comprido (Campo Comprido) e hospitais Psiquiátrico Bom Retiro (Bom Retiro), das Nações e Oswaldo Cruz (situados no Alto da Rua XV), Cajuru (Cajuru), Erasto Gaertner e São Carlos (localizados no Jardim das Américas), Nossa Senhora da Luz (Prado Velho) e do Trabalhador (Portão).

Esse procedimento, a partir de 1998, passou a ser alvo de críticas e questionamentos por parte da população do entorno dos pontos de incineração quanto à eficiência e real eficácia do método adotado, principalmente após divulgação de muitas irregularidades detectadas por grupos ambientalistas, destacando-se dentre elas os locais inadequados para queima do lixo hospitalar; a inadequada impermeabilização do solo; a separação de lixo executada de forma incorreta; a altura das chaminés fora dos padrões estabelecidos; a ausência de monitoramento periódico sobre a qualidade do ar expelido pela chaminé dos caminhões incineradores; o desacato às normas que determinam que a incineração deve ocorrer fora de área urbana; o uso inadequado de equipamento de proteção individual pelos operadores das máquinas e equipamentos (GAZETA DO POVO, 23/10/ 98, p. 14).

Em 1999 essas inquietações deram origem à Ação Civil Pública $n^{\circ} 18893$, movida contra a Prefeitura Municipal de Curitiba, Secretaria Municipal do Meio Ambiente e CAVO, motivo pelo qual, no final de 2001 , foi suspenso o método de tratamento de RSSS pela incineração nesse município. A partir desse ano, todos os resíduos infectantes, inclusive os perfuro-cortantes, gerados pelas empresas de saúde de Curitiba, passaram a ser aterrados em valas sépticas em seu destino final.

\section{DESTINO FINAL DOS RSSS EM CURITIBA: ATERRO EM VALAS SÉPTICAS}

Entende-se por disposição ou destino final de RSSS o confinamento desses resíduos em vala séptica ou, depois de haverem sido submetidos a um tratamento como a desinfecção, esterilização ou incineração, em aterro sanitário.

Pela confinação em valas sépticas, "os RSSS, sem sofrer compactação a fim de não romper os invólucros que os acondicionam, são tratados através de reação exotérmica (cal virgem e água), sendo em seguida recobertos por terra" (BRASIL, 2001, p. 82).

Em Curitiba, adotou-se o método de destino final de RSSS em valas sépticas em 1988, caracterizandose, inicialmente, como provisório e alternativo, a ser utilizado até o final do mês de julho de 1989. Posteriormente, esses resíduos passariam a ser tratados pelo processo de incineração, pois o Poder Público municipal previa a implantação de um incinerador central, que entraria em operação nesse mesmo ano, em conformidade com a Lei Municipal n 6866/86 (GAIESKI, 1991, p. 295).

No entanto, o método de aterramento de RSSS em valas sépticas continuou posteriormente sendo utilizado para o destino final dos resíduos infectantes produzidos pelas empresas de saúde de Curitiba e de outros municípios de sua região metropolitana, tais como Campina Grande do Sul, Colombo, Fazenda Rio Grande, Pinhais e São José dos Pinhas, pois o projeto de instalação do incinerador central para tratamento desses resíduos não se concretizou.

De acordo com o processo de destino final em valas sépticas, os resíduos são aterrados diariamente em uma vala aberta por funcionários, auxiliados por uma máquina retro-escavadeira. Ao fim do dia ou do serviço, a vala é coberta por uma camada de aproximadamente um metro de terra, disposta de maneira côncava para facilitar o escoamento de águas superficiais. A utilização desse método, segundo PMC (1997, p. 11), representa uma solução de baixo custo para o destino final de resíduos infectantes, pois dispensa o emprego de sistema de drenagem e tratamento de líquidos percolados, oriundos da degradação biológica de resíduos, necessitando, portanto, de área menor do que a requerida para instalação de aterro sanitário.

A concessão de licença de operação das atividades relacionadas ao aterramento dos resíduos infectantes em valas sépticas é de responsabilidade do Instituto 
Ambiental do Paraná (IAP), em atendimento ao art. 8, inciso III da Resolução $n^{\circ}$ 237/97-Conama e ao art. 2, inciso III da Resolução SEMA/IAP de 1998, devendo ocorrer periodicamente, com prazo não superior a 120 dias.

\section{QUANTIDADE DE RSSS TRATADOS PELA INCINE- RAÇÃO OU DESTINADOS ÀS VALAS}

A partir da adoção do método de aterramento de RSSS em valas sépticas, ocorrido em 1989, o Departamento de Limpeza Pública do município de Curitiba passou a desenvolver um rígido controle e aferição da quantidade de resíduos infectantes produzidos nesse e em alguns outros municípios da região metropolitana de Curitiba (Campina Grande do Sul, Colombo, Fazenda Rio Grande, Pinhais e São José dos Pinhais), destinados às valas sépticas. A pesagem dos veículos transportadores de RSSS é realizada a cada viagem.

Dessa maneira, desde 1989, ao final de cada ano é elaborada uma tabela dos resíduos infectantes incinerados ou aterrados, acrescida aos anos anteriores, por meio da qual é possível averiguar a quantidade total de resíduos produzidos pelas empresas de saúde, cadastradas no programa de coleta seletiva ou que solicitam serviços de remoção de resíduos infectantes ao órgão competente.
Constatou-se, mediante dados fornecidos pelo Departamento de Limpeza Pública de Curitiba, que durante o período compreendido entre janeiro de 1996 e dezembro de 2001 foram incinerados cerca de 1.217,60 toneladas de resíduos infetantes. O gráfico 1 demonstra a evolução percentual do desenvolvimento do método de incineração nesse período e permite averiguar o ápice do processo dessa atividade.

O método de incineração foi sendo utilizado gradativamente, justificando a ocorrência de crescimento lento e progressivo no período 1996-1997, com acréscimo de $84,97 \%$ de resíduos incinerados. A acentuada curva ascendente revela que o ápice do processo de incineração verificou-se durante o binômio 1998-1999, com aumento de cerca de $154 \%$. A curva descendente demonstra a redução abrupta da utilização do método de incineração verificada a partir de 2000 , com a eliminação desse método de tratamento de resíduos infectantes ao final de 2001.

Durante o período compreendido entre janeiro de 1989 e dezembro de 2001 , cerca de $48.420,90$ toneladas de resíduos infectantes foram depositadas nas valas sépticas, bem como as escórias e cinzas provenientes do material incinerado.

Durante os anos de 1989 a 1997, a totalidade dos RSSS era depositada nas valas sépticas em seu destino final. A curva ascendente do período revela que, aos poucos, foi ocorrendo a adesão das empresas de saúde

GRÁFICO 1 - TAXADE RSSS TRATADOS PELO PROCESSO DAINCINERAÇÃO

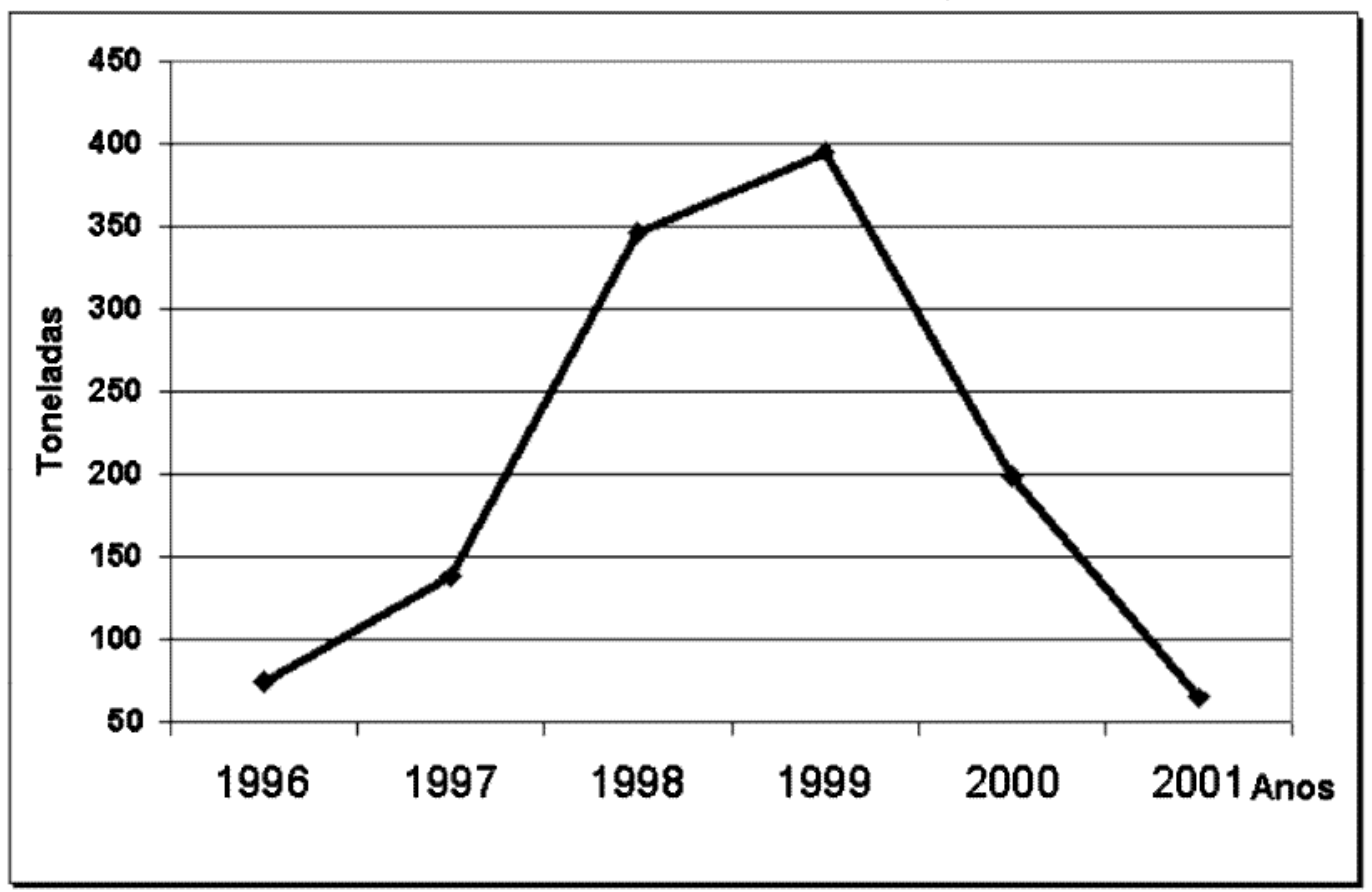

FONTE: SPINA, 2003, p. 73 
GRÁFICO 2 - RSSS DESTINADOS ÀS VALAS SÉPTICAS, DE 1989 A 2001

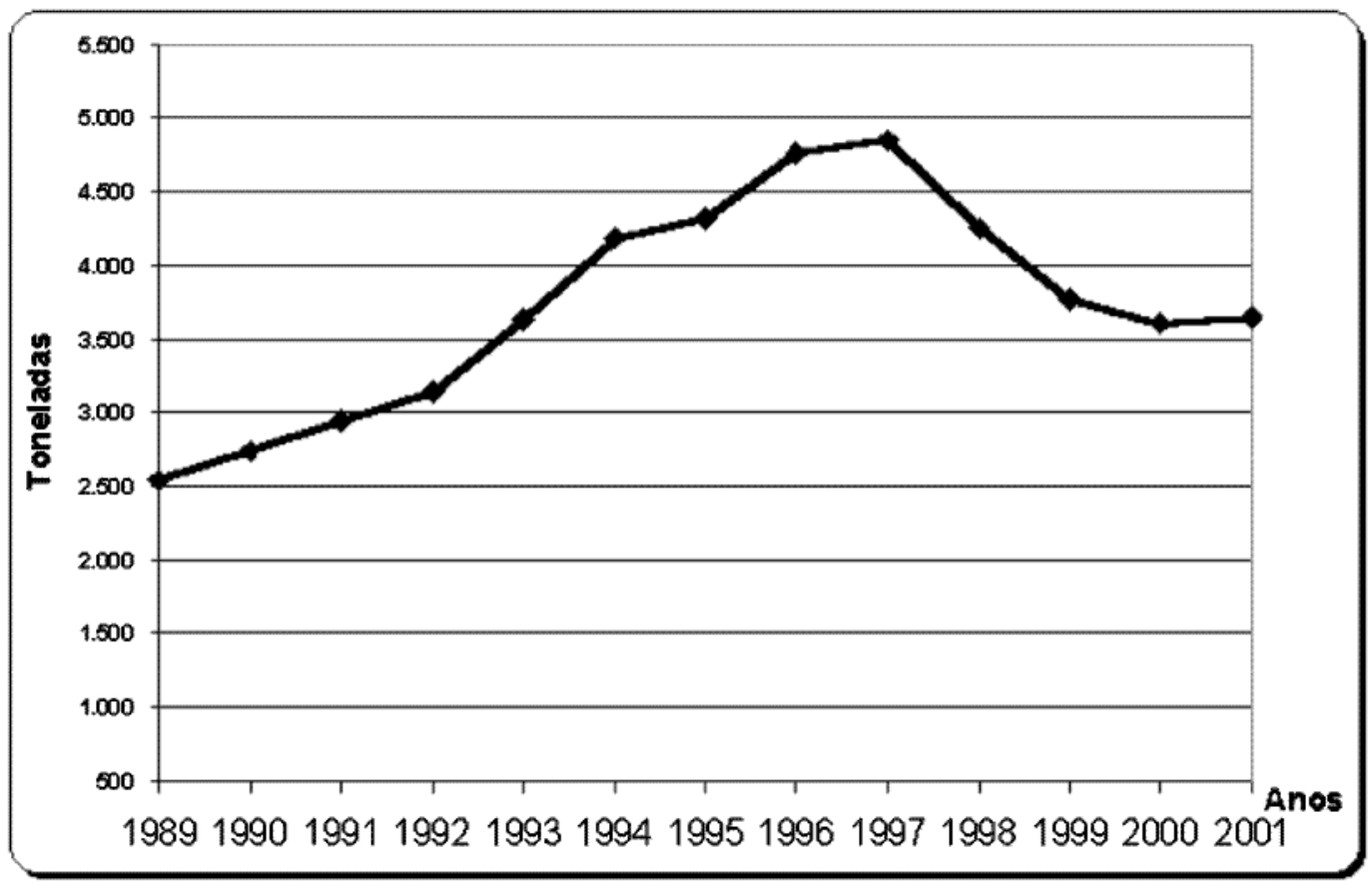

FONTE: SPINA 2003, p. 70.

ao programa de coleta seletiva proposto pela municipalidade. Durante os anos de 1998 a 2000 houve redução de RSSS às valas sépticas, em virtude da utilização concomitante do processo de incineração, em equipamento móvel, de parte desses resíduos. Posteriormente a redução estabilizou-se, pois o processo de incineração foi sendo desativado gradualmente, com encerramento ocorrido em dezembro de 2001.

Infere-se que durante o período contemplado pela pesquisa - 1989 a 2001 - foram produzidas cerca de $49.638,50$ toneladas de resíduos infectantes pelas empresas de saúde de Curitiba e demais municípios que utilizaram as valas sépticas como receptora dos resíduos gerados (SPINA, 2003, p. 69).

\section{CONDIÇÕES FÍSICAS DAÁREA DAS VALAS SÉPTI- CAS E OCUPAÇÃO DO ENTORNO}

A área das valas sépticas, que mede em sua totalidade cerca de $92.000 \mathrm{~m}^{2}$, dos quais $54.000 \mathrm{~m}^{2}$ efetivamente aproveitados para a instalação das valas, está localizada no bairro Cidade Industrial de Curitiba (CIC), distante cerca de $12 \mathrm{~km}$ do centro de Curitiba, nas proximidades da confluência das avenidas João Bettega e Juscelino K. Oliveira ou Contorno Sul. Essa área está situada em topo de morro de $930 \mathrm{~m}$.a. e apresenta solos impermeáveis, com forte presença de argilito da formação Guabirotuba. A região é banhada pelo rio Barigüi e seus afluentes, e o lençol freático localiza-se a doze metros de profundidade (SPINA, 1999, p. 139).

$\mathrm{Na}$ atualidade, esse local encontra-se totalmente desmatado, com exposição de solo nu. Em seu entorno Norte, Noroeste, Oeste, Sudoeste e Sul detectam-se manchas da vegetação nativa, moradias campestres e indústrias, além de áreas desnudas. A Nordeste, Leste e Sudeste há forte concentração de conjuntos residenciais, entremeados por indústrias, rodovias e avenidas que comportam alto tráfego, além de significativa presença de arruamentos planejados, em traçado tabuleiro.

A análise cronológica dessa ocupação, realizada por meio das fotografias aéreas dos períodos correspondentes a 1980, 1985, 1992 e 2000, demonstrou que em 1980 a avenida Juscelino K. de Oliveira já cortava a região, o topo de morro encontrava-se parcialmente desmatado e a ocupação nitidamente residencial encontrava-se estabelecida além dos limites indicados por Bertussi Filho (1994, p. 53) e lbam (2001, p. 154), ou seja, fora do raio de $1000 \mathrm{~m}$ de distância das valas. No entanto, nos anos posteriores, parte da área aquém desse limite foi sendo gradativamente ocupado pela população, com edificação de moradias e instalação de inúmeras empresas comerciais e industriais. 
Em 1985 ocorreu forte ocupação residencial a Leste da área das valas sépticas, estendendo-se até as margens do rio Barigüi, com acentuado adensamento populacional efetuado, sobretudo, entre as ruas Cid Campelo e João Bettega, numa distância inferior a 1000 $\mathrm{m}$ em relação à localização da área das valas sépticas, desrespeitando as normas vigentes. ${ }^{3}$

A porção Norte dessa área, no entanto, continuava a apresentar densa vegetação, sem vestígios de ocupação humana adensada até esse período. Essa situação se reverteu a partir da década de 1990, quando essa área passou a ser desmatada e densamente ocupada, fenômeno esse que se intensificou a partir de 1992, estendendo-se para outras direções.

No ano 2000 o adensamento populacional aproximou-se ainda mais da área das valas sépticas, principalmente em suas porções Norte, Nordeste, Leste, Sudeste e Sul, locais onde a ocupação tornou-se bastante nítida e adensada. Assim, verificou-se que a evolução e transformação que ocorreram durante o período analisado modificaram as prerrogativas iniciais de área suburbana ou rural do entorno, que adquiriram feições nitidamente urbanizadas.

\section{IMPLICAÇÕES SOCIOAMBIENTAIS DECORRENTES DO DESTINO FINAL DOS RSSS}

O destino final dos RSSS em valas sépticas apresenta sérios inconvenientes, pois as áreas utilizadas para esse fim transformam-se em passivos ambientais, não sendo indicadas para atividades produtivas por muitos anos ou décadas. Além disso, esses resíduos tornamse agentes potencialmente causadores de poluição do ar, do solo e das águas superficiais e subterrâneas da área, pela carga contaminante que eles apresentam.

O estudo sobre o método de destino final de RSSS em valas sépticas adotado pelo Poder Público municipal de Curitiba, contemplando o período de 1989 a 2001, revelou que esse procedimento suscita sérias indagações quanto ao comprometimento da qualidade de vida e equilíbrio ambiental, a médio e longo prazos, destacandose dentre elas: a) Da totalidade das empresas geradoras de RSSS em Curitiba, representada por 6.272 empresas, apenas 862 ou cerca de $13,7 \%$ encontravam-se cadastradas ao programa de coleta seletiva denominado "Lixo que não é lixo hospitalar". Essa constatação demonstra que a maioria das empresas, embora pertencentes à categoria de pequenas geradoras, pela baixa quantidade de resíduos infectantes que produzem, não estavam vinculada ao programa de coleta seletiva periódica. Por outro lado, não há indicativos capazes de sinalizar que os resíduos produzidos nesses pequenos geradores estavam sendo encaminhados para os locais apropriados em seu destino final.

b) Dentre as 862 empresas cadastradas ao programa de coleta seletiva em Curitiba em 2001, destacava-se a categoria representada pelos 44 hospitais, os maiores geradores de resíduos infectantes instalados no município, o que revela que parte considerável dos RSSS estava sendo destinado de forma adequada, apurando-se, por estimativa, que eles geram, em média, cerca de $8.052,69 \mathrm{~kg} / \mathrm{dia}$, dentre os quais $4.212,60 \mathrm{~kg} /$ dia de resíduos infectantes destinados às valas sépticas. ${ }^{4}$ No entanto, a maioria das empresas, ou seja, cerca de 5.410 , embora inseridas na categoria de pequenas geradoras, não estando cadastradas ao programa de coleta seletiva, estavam destinando seus resíduos a locais inadequados, possivelmente ao aterro sanitário. Esclarece-se, porém que o Poder Público local atendia também solicitações de remoção de resíduos infectantes mediante solicitação da empresa, quando necessário, a fim de conceder-lhes destino final adequado.

c) Presume-se que os RSSS, inclusive os caracterizados como infectantes, quando não são selecionados e segregados convenientemente na fonte geradora, conforme as normas contidas no programa da coleta seletiva de Curitiba, são destinados, na condição de resíduos comuns ou domésticos, ao aterro sanitário da Cachimba, inclusive os perfuro-cortantes e patogênicos, podendo vir a contaminar o solo e lençol freático do local, bem como o entorno da área onde são dispostos. Ressalta-se, no entanto que, ao final do período analisado, para obtenção de alvará de licenciamento, as novas

${ }^{3}$ Ressalta-se que, em função das características patogênicas apresentadas pelos RSSS, Bertussi Filho (1994, p. 53) e Ibam (2001, p. 154) citam a distância de $1.000 \mathrm{~m}$ de raio da área das valas sépticas como espaço mínimo a ser preservado, como garantia de redução de problemas à saúde pública, devendo a mesma área manter-se livre de ocupação produtiva ou moradia, ou seja, sem instalação de empresa comercial, industrial ou imóvel residencial, tolerando-se, no entanto, um limite máximo de 200 habitantes (IBAM, 2001, p. 154).

4 Tomou-se como parâmetro o dispositivo da Divisão de Organização Hospitalar, do Ministério da Saúde, que prevê uma taxa média de $1,3 \mathrm{~kg} / \mathrm{leito} / \mathrm{dia}$, dos quais $0,680 \mathrm{~kg}$ constituídos de resíduos sépticos e 0,620 kg de resíduos não sépticos (BERTUSSI FILHO, 1994, p. 29). Em Curitiba, apurou-se a existência de cerca de 6.195 leitos ofertados pelos hospitais à população, ao final de 2001. Estimou-se que eles são responsáveis pela geração de $3.840,09 \mathrm{~kg} / \mathrm{dia}$ de resíduos sépticos, destinados às valas sépticas e 4.212,60 kg/dia de resíduos não sépticos, com características de resíduos comuns e/ou recicláveis, totalizando 8.052,69 kg/dia. 
empresas de saúde de Curitiba deviam comprometer-se a acatar as normas contidas no Programa de Gerenciamento de Resíduos Sólidos de Saúde (PGRSS) e gerenciar corretamente os RSSS produzidos.

d) Na possibilidade de estarem sendo desti-nados com os demais RSU, os resíduos infectantes, sobretudo os perfuro-cortantes produzidos pelos pequenos geradores, representam potencial perigo à comunidade, principalmente ao considerar que parte dos RSU são dispostos nas calçadas à espera da coleta pública, podendo ser os invólucros que os acondicionam facilmente rompidos, e causar ferimentos e contaminação nas pessoas que transitam pelo local e às que manipulam os RSU à procura de material reciclável.

e) As empresas que não acatavam as determinações sobre a correta segregação dos resíduos de acordo com o programa proposto pela coleta seletiva "Lixo que não é lixo hospitalar", acabavam por enviar a totalidade dos resíduos produzidos para as valas sépticas, ocupando espaço que poderia ser poupado se os resíduos recicláveis e comuns fossem enviados aos seus respectivos destinos finais, quais sejam, usina de reciclagem e aterro sanitário, respectivamente.

f) Os gerentes administrativos e funcionários da maioria das empresas de saúde geradoras de resíduos infectantes desconhecem o local de aterramento bem como os procedimentos técnico-operacionais que envolvem as questões ambientais na fase de destino final desses resíduos. Assim, entende-se que é necessário promover a divulgação desses procedimentos e das características do local de aterramento dos RSSS, a fim de que haja maior conscientização e comprometimento dos funcionários das empresas de saúde quanto à real necessidade de se acatarem as normas corretas de segregação, acondicionamento e armazenamento dos resíduos infectantes.

g) Como fator agravante, destaca-se a ausência, por parte do órgão competente, de monitoramento anual das águas subterrâneas e das águas superficiais da referida área, pertencentes à bacia do rio Barigüi, durante o período contemplado nesta pesquisa. Ressalta-se no entanto que, se elas existem, não estão sendo divulgadas ou disponibilizadas ao público, contrariando dispositivos da Lei Municipal $n^{\circ} 7.833 / 91$.

A pesquisa revelou ainda que, sendo as valas sépticas construídas tecnicamente dentro dos padrões técnicos estabelecidos, observando-se as devidas recomendações legais concernentes à preservação ambiental, as possíveis contaminações do solo e do lençol freático são passíveis de serem controladas ou evitadas a curto e médio prazos, apesar do alto potencial contaminante que esses resíduos apresentam. Todavia, para evitar problemas e danos ao meio ambiente e à saúde da população, e também para impedir que essas questões ganhem dimensão descontrolada em futuro próximo ou remoto, em função do descarte de RSSS em valas sépticas ou inadequadamente em aterro sanitário, é necessário que se adotem métodos alternativos de tratamento e destino final que possam garantir a redução das nefastas conseqüências ao meio ambiente e à sociedade.

A pesquisa também revelou que o método de utilização de valas sépticas não permite acompanhamento do processo degenerativo do material aterrado, cujas características são profundamente heterogêneas. Assim, considerando-se a possibilidade de as empresas geradoras ou o Poder Público continuarem recorrendo ao método de aterramento de RSSS, propõem-se alguns procedimentos operacionais, a fim de auxiliar nesse acompanhamento:

- Seleção, nas unidades internas das empresas de saúde, do material infectante de acordo com o tipo ou categoria da matériaprima utilizada em sua fabricação, considerando-se o tempo necessário para a degradação desses resíduos;

- Construção de valas específicas para o aterro dos diferentes resíduos, selecionadas de acordo com as características peculiares referentes à decomposição do material de que são compostos;

- Áreas selecionadas para a instalação de valas receptoras dos diferentes resíduos, conforme as características inerentes de cada categoria;

- Realização periódica de análise química do solo para verificação de possível contaminação prejudicial ao ambiente e à sociedade;

- Realização periódica de análise da água dos rios próximos às valas sépticas para averiguação de seu grau de potabilidade;

- Divulgação da real condição ambiental da área das valas sépticas para conhecimento público, conforme Lei Municipal ${ }^{\circ} 7.833 / 91$; (SPINA, 2003, p. 133).

Os estudos realizados demonstram que os RSSS considerados infectantes merecem tratamento e destino final que garantam a destruição total de suas características patogênicas. A incineração, apesar dos altos investimentos requeridos em sua instalação e manutenção, representa um método alternativo de tratamento de RSSS capaz de garantir o extermínio dos agentes patogênicos e de reduzir em até noventa por cento o volume dos resíduos a receber destino final, reduzidos a 
cinzas e escórias. Nesse caso, devem-se instalar equipamentos de alta tecnologia, dotados de eficientes filtros, capazes de evitar poluição atmosférica. O destino final dos subprodutos também requer cuidados especiais, na condição de resíduos perigosos, pela alta concentração de dioxinas e furanos que podem apresentar.

A respeito da incineração, nota-se que nem sempre há consenso entre os legisladores e pesquisadores brasileiros sobre a conveniência ou inconveniência de sua adoção. Isso tem gerado muita insegurança nos gerenciadores de RSSS, pois nas últimas décadas foram aprovadas leis que ora apóiam e ora desaprovam tal prática.

Com relação a essa temática vale destacar que, na atualidade, a RDC 306/04, item 1.6, desde que sejam obedecidas as disposições contidas na Resolução CONAMA 316/2002, indica o método da incineração para tratamento dos resíduos infectantes como um dos processos a ser utilizado no tratamento aos resíduos infectantes gerados pelas empresas prestadoras de serviços de saúde, visando a eliminação de risco de contaminação e de dano ao meio ambiente.

\section{GERENCIAMENTO DE RSSS CONFORME LEGISLA- ÇÃO ATUAL}

O gerenciamento integrado dos RSSS, desenvolvido em parceria entre Poder Público e empresas de saúde de Curitiba, está enfrentando na atualidade um impasse, o que tem gerado sérias polêmicas quanto à competência e continuidade dos serviços referentes à coleta, transporte e destino final dos resíduos infectantes.

Essa situação conflitante é decorrente da aprovação, em 7 de dezembro de 2004, da Resolução da Diretoria Colegiada - RDC 306/04 - que, reiterando os dispositivos das Resoluções Conama $n^{\circ}$ 05/93 e ${ }^{\circ} 283 /$ 01, considera serem as empresas geradoras de RSSS os agentes responsáveis por todas as fases de gerenciamento e manuseio dos resíduos que produzem, da geração ao destino final.

A Resolução RDC 306/04 concedeu um prazo de seis meses, a contar da data de sua publicação, para que as empresas de saúde do território brasileiro possam desenvolver seus Planos de Gerenciamento dos Resíduos de Serviços de Saúde (PGRSS) e submetam esses planos aos órgãos competentes para aprovação (RDC 306/04, cap. V).

Dessa forma, em Curitiba, o Poder Público local, a partir do final do mês de abril de 2005, realizou o fechamento definitivo das valas sépticas, que já estavam no limite da capacidade de vida útil, e isentou-se da responsabilidade de continuar gerenciando parte dos
RSSS, incumbência essa que havia assumido desde o início de 1989, realizada em parceria com as empresas prestadoras de serviços de saúde do município.

Diante desse fato, novas questões se apresentam à discussão quanto à capacidade real dessas empresas de Curitiba em adotarem medidas ambientalmente responsáveis, diante da responsabilidade legal de gerenciar todas as fases das dez toneladas de resíduos infectantes produzidos diariamente na capital paranaense, na atualidade. Alguns dos questionamentos imediatos que podem ser apontados são:

- $\quad$ Essas empresas estão realmente preparadas estrutural e tecnicamente para gerenciar todas as etapas dos resíduos infectantes que produzem?

- $\quad$ Os serviços que até então vinham sendo desenvolvidos pelo Poder Público local, tais como coleta, transporte, tratamento e destino final dos RSSS, serão contemplados adequadamente, sem risco à saúde pública e ao meio ambiente?

- As pessoas envolvidas na gestão dos RSSS, das grandes, médias e pequenas empresas geradoras de resíduos infectantes, estão realmente conscientes sobre a necessidade de promover um tratamento eficiente e eficaz aos resíduos infectantes, e conhecem as implicações socioambientais que o destino final desses resíduos podem causar?

\section{CONSIDERAÇÕES FINAIS}

Os resultados da pesquisa permitiram afirmar que durante a vigência do Gerenciamento Integrado dos RSSS em Curitiba, as etapas de manejo compreendidas desde a geração até a armazenagem externa, desenvolvidas pelos grandes geradores de resíduos infectantes, foram realizadas de maneira adequada, sob a responsabilidade da Comissão de Controle de Infecção Hospitalar - CCIH, Comissão Interna de Prevenção de Acidentes - CIPA e Vigilância Sanitária.

Quanto ao compromisso assumido pelo Poder Público, embora tenham sido detectadas algumas irregularidades durante o período estudado, que suscitaram preocupações em algumas fases ou etapas, principalmente aos que se referem ao tratamento e destino final de tais resíduos, constata-se que, no contexto, considerando-se a totalidade dos procedimentos adotados e acatados nas diversas etapas desse gerenciamento, houve bons resultados, sobretudo quanto aos obtidos pelo programa de coleta seletiva, que propiciou a redução de resíduos enviados às valas sépticas e também quanto 
ao controle das empresas cadastradas e atendidas pelos serviços públicos disponibilizados.

Destaca-se também que o mapeamento das empresas prestadoras de serviços de saúde existentes em Curitiba revelou que o espaço urbano desse município, sobretudo os bairros centrais, encontra-se intrinsicamente marcado pela presença de resíduos infectantes gerados nessas empresas, os quais requerem cuidados especiais em suas todas as fases de seu gerenciamento, a fim de garantir a redução das implicações negativas que os mesmos possam causar a esse espaço e a sua respectiva população.

Diante das novas perspectivas de gerenciamento dos RSSS tão somente pelas empresas geradoras, em atendimento aos dispositivos da RDC 306/04, cabe à sociedade curitibana em geral e a cada cidadão em particular a tarefa de apontar as falhas e salientar as atitudes corretas que forem sendo observadas, no sentido de colaborar para que todos possam usufruir de um ambiente saudável e melhor qualidade de vida.

\section{REFERÊNCIAS}

AGÊNCIANACIONAL DE VIGILÂNCIASANITÁRIA-ANVISA. Resolução da Diretoria Colegiada n. 306 de 7 de dezembro de 2004. Dispõe sobre o regulamento técnico para o gerenciamento de resíduos de serviços de saúde. Diário Oficial da República Federativa do Brasil, Brasília, 10 dez. 2004.

BERTUSSI FILHO, Luis A. Resíduos de serviços de saúde: gerenciamento, tratamento e destinação final. Apostila do curso promovido pela Associação Brasileira de Engenharia Sanitária e Ambiental (ABES), Palmas, TO, 1994.

BRASIL. Ministério da Saúde. Gerenciamento de Resíduos de Serviços de Saúde. Projeto Reforsus, Brasília, 2001.

CALDERONI, Sabetai. Os bilhões perdidos no lixo. São Paulo: Humanitas, 1998.

COMEC. Fotografia aérea pancromática. Escala: 1:8.000. 94748, 1985.

CONSELHO NACIONAL DO MEIO AMBIENTE - CONAMA. Resolução n. 05/93. Brasília, 1993. (incompleto)

Resolução n. 283 de 12/7/2001. Brasília, 2001. (incompleto)

CURITIBA. Prefeitura Municipal. Fotografia aérea monocromática. Escala: 1:8.000. 9-4748, 1985.

GAIESKI, Antonio A. Curitiba: o gerenciamento dos resíduos sólidos - passado, presente e perspectivas. Florianópolis, 1991. Dissertação (Mestrado em Geografia) - Universidade Federal de Santa Catarina.

LIXO HOSPITALAR de Curitiba está sendo queimado irregularmente. Gazeta do Povo, Curitiba, 23 out. 1998. p. 14.

INSTITUTO BRASILEIRO DE ADMINISTRAÇÃO MUNICIPAL. Gestão integrada de resíduos sólidos. Manual de gerenciamento integrado de resíduos sólidos. 2. ed. Rio de Janeiro, [s.n.], 2001.

IAP/GTZ. Fotografia aérea pancromática. Escala: 1:20.000. 26047 Fx04, 1992.

ITC-PR. Fotografia aérea pancromática. Escala: 1:25.000. 49668, 1980.

CURITIBA. Prefeitura Municipal. Resíduos sólidos urbanos. Apostila da Secretaria Municipal do Meio Ambiente. Departamento de Limpeza Pública. Curitiba, 1997.

Resíduos sólidos urbanos no Município de Curitiba. Apostila da Secretaria Municipal do Meio Ambiente. Departamento de Limpeza Pública. Curitiba, 1999.

Tabela de RSSS coletados em Curitiba no período de 1989 a 2001. Departamento de Limpeza Pública. Curitiba, 2002.

Tabela de RSSS coletados em Curitiba no período de 1996 a 2001. Departamento de Limpeza Pública. Curitiba, 2002.

PROMOTORIA PÚBLICADO ESTADO DO PARANÁ. Ação Civil Popular n.- 18893, Curitiba: Vara do Meio Ambiente, 10 fev. 1999.

SPINA, Maria Inez A. P. Diagnóstico sobre os resíduos sólidos dos serviços de saúde do município de Curitiba. Curitiba, 1999. Monografia (Especialização em Gestão e Análise Ambiental) - Departamento de Geografia, UFPR.

Análise do gerenciamento dos resíduos sólidos dos serviços de saúde em Curitiba, com ênfase no tratamento e destino final, e implicações socioambientais. Curitiba, 2003. Dissertação (Mestrado) - Departamento de Geografia, UFPR.

SUDERSHA-PR. Fotografia aérea colorida. Escala: 1:30.000. FX008, 2000. 